\title{
AS POLÍTICAS PÚBLICAS EDUCACIONAIS PARA AS PESSOAS EM SITUAÇÃO DE PRIVAÇÃO DE LIBERDADE NO ESTADO DO AMAPÁ
}

Josiane Pantoja Ferreira ${ }^{1}$

\section{RESUMO}

Este artigo apresenta um conjunto de normativas que balizam a oferta da educação às pessoas em situação de privação de liberdade no Estado do Amapá. O objetivo deste trabalho é contribuir com o debate da Educação de Jovens e Adultos (EJA), enfocando o perfil do público alvo dessa modalidade de ensino e as políticas públicas educacionais para as pessoas que estão no cumprimento da pena de reclusão. O resultado da pesquisa possibilita uma reflexão das políticas educacionais voltadas para o ambiente penitenciário do Amapá, e evidencia que historicamente a EJA é marginalizada e que essa característica se reflete na prisão de forma intensificada.

Palavras-Chave: Políticas Públicas, EJA, Pessoa em situação de privação de liberdade.

\section{PUBLIC EDUCATIONAL POLICIES FOR PEOPLE IN DISTRIBUTION OF FREEDOM IN THE STATE OF AMAPÁ}

\section{ABSTRACT}

This article presents a set of regulations that guide the provision of education to people in situations of deprivation of liberty in the State of Amapá. The objective of this work is to contribute to the debate on Youth and Adult Education (EJA), focusing on the profile

\footnotetext{
${ }^{1}$ Doutoranda no Programa de Pós-Graduação em Educação da Amazônia, Associação Plena em Rede, do Núcleo de Estudos Transdisciplinares em Educação Básica, da Universidade Federal do Pará. ORCID: https://orcid.org/0000-0002-2685-6101. E-mail: josianepantoja@hotmail.com
} 
of the target audience of this type of teaching and public educational policies for people who are serving their sentences. The result of the research makes it possible to reflect on educational policies aimed at the prison environment in Amapá, and shows that historically EJA has been marginalized and that this characteristic is reflected in the prison in an intensified way.

Keywords: Public Policies. EJA. Person in a situation of deprivation of liberty.

\section{POLÍTICAS EDUCATIVAS PARA PERSONAS EN DISTRIBUCIÓN DE LIBERTADEM EL ESTADO DE AMAPÁ}

\section{RESUMEN}

Este artículo presenta un conjunto de normas que orientan la provisión de educación a personas en situación de privación de libertad en el estado de Amapá. El objetivo de este trabajo es contribuir al debate sobre la Educación de Jóvenes y Adultos (EJA), centrándose en el perfil del público destinatario de este tipo de enseñanza y políticas públicas educativas para las personas que están cumpliendo condena. El resultado de la investigación permite reflexionar sobre las políticas educativas dirigidas al ambiente carcelario en Amapá, y muestra que históricamente EJA ha sido marginada y que esta característica se refleja en la prisión de manera intensificada.

Palabras clave: Políticas Públicas. EJA. Persona en situación de privación de libertad.

\section{INTRODUÇÃO}

O Brasil possui a terceira maior população carcerária do mundo. O Estado de São Paulo figura com a maior concentração de pessoas em situação de privação de liberdade, e com a menor quantidade está o Estado de Roraima. O Estado do Amapá apresenta o segundo menor percentual com 2.806 pessoas, 
conforme o levantamento nacional de informações penitenciárias atualizadas até junho de 2017 e publicado no ano de 2019 (DEPEN, 2019).

Segundo os dados oficiais do Departamento Penitenciário Nacional (DEPEN), o grau de escolaridade das pessoas em situação de privação de liberdade é composto por: 3,5\% analfabetos; 5,85\% alfabetizados; 51,35\% Ensino Fundamental Incompleto; 13,15\% Ensino Fundamental Completo; 14,98\% Ensino Médio Incompleto; 9,65\% Ensino Médio Completo; 0,97\% Ensino Superior Incompleto; 0,56\% Ensino Superior Completo; 0,04\% ensino acima de Superior Completo (DEPEN, 2019, p. 34). Dessas informações depreende-se que o grau de escolaridade é baixíssimo, o que revela a necessidade de discussão da educação para a pessoa que está presa e sairá.

O estudo, inicialmente, apresenta o contexto da educação de jovens e adultos, e traz à baila a educação como um direito de todos, conforme diversas legislações nacionais e internacionais, e apresenta um breve histórico dessa modalidade de ensino que integra a educação básica e atende a um público especifico, que por diversas circunstâncias não tiveram condições de acesso e/ou permanência na educação escolar no período considerado adequado.

Em seguida, no tópico "Políticas públicas e educação de jovens e adultos encarcerados" são abordadas algumas peculiaridades das pessoas em situação de privação de liberdade. Vale ressaltar que a educação no ambiente penitenciário é um direito, e não um benefício.

No tópico das políticas educacionais para o sistema penitenciário do Amapá é realizado o levantamento dos aportes legais, que embasam a discussão da oferta educativa no sistema prisional amapaense, tais como: Constituição Estadual do Amapá, Plano Estadual de Educação instituído pela lei $n^{\circ} 1.907$, de 24 de junho de 2015, o Estatuto Penitenciário do Estado do Amapá promulgado pela lei $n^{\circ}$ 0692, de 11 de junho de 2002, O Plano Diretor do Sistema Penitenciário do Estado do Amapá, a Resolução Normativa No 57/2015 do Conselho Estadual de Educação (CEE/AP), que regulamenta a oferta da educação de jovens e adultos e a educação profissional e tecnológica, para todas as pessoas em 
situação de privação de liberdade e a Portaria 001/2019 da Vara de Execuções Penais (VEP), de 12 de março de 2019, que disciplina a remição pela leitura.

Desse modo, o artigo busca contribuir, mesmo que de forma diminuta, com a discussão da oferta educativa no sistema prisional do Estado do Amapá.

\section{O CONTEXTO DA EDUCAÇÃO DE JOVENS E ADULTOS}

A educação é um direito de todos, englobando, portanto, os jovens e adultos, essa garantia vem expressamente consignada em diversas legislações internacionais e nacionais, tais como: Declaração Universal dos Direitos Humanos de 1948; Constituição Federal de 1988, Lei de Diretrizes e Bases da Educação nº 9.394 de 1996; Plano Nacional de Educação Lei no 13.005 de 2014, entre outras.

A educação de jovens e adultos é um campo amplo, complexo e heterogêneo, porque envolve as dimensões sociais, política, econômica e cultural, que estão diretamente ligadas com as questões das desigualdades sociais enfrentadas por grande parte da sociedade brasileira, ou seja, a classe social pauperizada.

A educação, por mais que não consiga responder a todas as demandas sociais, como muitos messianicamente ou poeticamente esperam, ela se constitui em importante e fundamental instrumento de promoção social. Vale enfatizar que não é papel da educação erradicar os problemas sociais que assolam o Brasil. Segundo Freire (2007, p. 37), "Pensar a História como possibilidade é reconhecer a educação também como possibilidade. É reconhecer que se ela, a Educação, não pode tudo, pode alguma coisa".

As características das pessoas que frequentam a EJA são diversificadas, porém é predominante a presença de sujeitos das classes populares, onde geralmente são pardos e negros, que sobrevivem da economia informal, sem condições de segurança, habitação, saúde, e comumente trabalham durante o dia, e dispõem somente do período noturno para frequentar as aulas. Esse cenário marcado por discriminação e negação de direitos tende a se 
reproduzir, se políticas públicas não forem efetivadas, e se a escola não parar de homogeneizar e tentar invisibilizar as práticas sociais dos discentes jovens e adultos. Segundo Arroyo (2005, p. 22), "Não é qualquer jovem e qualquer adulto. São Jovens e adultos com rosto, com histórias, com cor, com trajetórias sócio-étnico-racial, do campo da periferia".

O percurso dos jovens e adultos são trajetos coletivos, pois:

Desde que a EJA é EJA esses jovens e adultos são os mesmos: pobres, desempregados, na economia informal, negros, nos limites da sobrevivência. São jovens e adultos populares. Fazem parte dos mesmos coletivos sociais, raciais, étnicos, culturais. O nome genérico: educação de jovens e adultos oculta essas identidades coletivas. Tentar reconfigurar a EJA implica assumir essas identidades coletivas. Trata-se de trajetórias coletivas de negação de direitos, de exclusão e marginalização, consequentemente a EJA tem de se caracterizar como uma política afirmativa e, como tal, tem de ser equacionada. Consequentemente tem de ir além das formas genéricas de tentar garantir direitos para todos. Trata-se de direitos negados historicamente (GIOVANETTI; GOMES; SOARES, 2005, apud ARROYO, 2005, p. 29 - 30).

A trajetória da EJA é carregada de preconceito, pois essa modalidade de ensino é ofertada predominantemente aos pobres, logo, é um ensino distinto do oferecido às pessoas de classe média e elite. Dessa forma o futuro profissional dos discentes nem sempre depende exclusivamente da educação, tendo em vista que a condição social ainda é um fator determinante.

Historicamente, as iniciativas do Governo Federal quanto à Educação de Jovens e Adultos tiveram caráter marginal. Até a década de 40, a escolarização de adultos era imaginada como uma extensão do ensino formal, essa concepção predominava na zona rural. Nos anos 50, a EJA era percebida como "[...] educação de base, como desenvolvimento comunitário." (GADOTTI, 2003, p.34). Além de tardiamente, as primeiras ações do Estado tiveram um princípio 
político e pedagógico eminentemente compensatório, caráter que predominou nas iniciativas subsequentes.

Nesse trajeto, é oportuno destacar a formulação de outra possibilidade. Segundo Gadotti (2003, p. 35), no término dos anos 50 emergiram duas proposições para a EJA, a primeira:

[...] entendida como educação libertadora, como "conscientização" (Paulo Freire) e a educação de adultos entendida como educação funcional (profissional), isto é, o treinamento de mão de obra mais produtiva, útil ao projeto de desenvolvimento nacional dependente (Grifo nosso).

$\mathrm{Na}$ década de 60, foram criados programas com viés democrático que objetivavam oportunizar a escolarização elementar de adultos, os principais programas foram: o Movimento de Educação de Base (MEB), Centro Popular de Cultura (CPC) e o Movimento de Cultura Popular (MCP). Esses programas foram interrompidos e reprimidos pelo golpe civil militar de 1964 (COSTA; OLIVEIRA, 2011).

Nos anos 70, as duas correntes de educação libertadora e de educação funcional permanecem, sendo a primeira compreendida como educação não formal, e a outra como suplência do ensino formal. Segundo Di Pierro (2005), nesse período, alguns segmentos sociais, influenciados pelas ideias de Paulo Freire, introduziram novas experiências no campo educacional, objetivando a criticidade, conscientização e a transformação social; os pilares da educação de jovens e adultos de Paulo Freire podem ser sintetizados na célebre frase: "[...] a leitura do mundo precede a leitura da palavra".

Nesse período de 70, durante o Governo Militar, foi instituído o MOBRAL (Movimento Brasileiro de Alfabetização), com concepções opostas às de Paulo Freire (GADOTTI, 2003). Essa política caracterizou um retrocesso, por não dar continuidade às ideias freireanas e por objetivar a legitimação do sistema ditatorial, para isso censurava, perseguia e reprimia quem se opunha aos preceitos do MOBRAL. Nesse período, foi criado o Ensino Supletivo, que reforçou o caráter compensatório da educação, que se caracteriza pela reposição da escolaridade não realizada na infância 
e adolescência. Esta iniciativa servia simplesmente para possibilitar o ensino às pessoas que não puderam estudar na idade adequada. É o predomínio da educação bancária (FREIRE, 1996).

O itinerário da EJA, no Brasil, pode ser divido em três fases, consoante aos ensinamentos de Gadotti (2003, p. 35-36):

$1^{\circ}$ De 1946 a 1958, onde foram realizadas grandes campanhas nacionais de iniciativa oficial, chamadas de "cruzadas", sobretudo para "erradicar o analfabetismo", entendido como uma "chaga", uma doença como a malária. Por isso se falava em "zonas negras de analfabetismo".

$2^{\circ}$ De 1958 a 1964. Em 1958 foi realizado o $2^{\circ}$ Congresso Nacional de Educação de Adultos, que contou com a participação de Paulo Freire. Partiu daí a ideia de um programa permanente de enfrentamento do problema de alfabetização que desembocou no Plano Nacional de Alfabetização de Adultos, dirigido por Paulo Freire e extinto pelo Golpe de Estado de 1964, depois de um ano de funcionamento. [...]

$3^{\circ} \mathrm{O}$ governo militar insistia em campanhas como

a "Cruzada do ABC" (Ação Básica Cristã) e posteriormente, com o MOBRAL.

Com a redemocratização do Brasil (1985), o MOBRAL foi extinto, e criou-se a Fundação Educar, com finalidades mais democráticas, porém sem previsão de recursos financeiros (GADOTTI, 2003).

Nesse período, também se identificam novidades em relação a essa modalidade educativa, a de maior relevo é a promulgação da denominada constituição cidadã de 1988, que abriu caminhos para a consolidação dos direitos sociais, dentre eles a educação. A CF assegura em seu artigo 205, a obrigatoriedade, e não somente a gratuidade, do Ensino Fundamental aos que a ele não tiveram acesso na idade própria, incluindo, portanto, jovens e adultos, vejamos:

A educação, direito de todos e dever do Estado e da família, será promovida e incentivada com a colaboração da sociedade, visando ao pleno 
desenvolvimento da pessoa, seu preparo para o exercício da cidadania e sua qualificação para o trabalho (BRASIL, 1988).

Essa modalidade educativa, apesar da garantia do direito no plano jurídico, foi caracterizada pela falta de sistematização de políticas públicas eficazes que garantissem acesso, permanência e qualidade ao ensino para jovens e adultos.

Com o processo de redemocratização passou-se então a discutir o caráter compensatório da educação de jovens e adultos. Durante os primeiros estudos para a construção da nova Lei de Diretrizes e Bases da Educação Nacional (LDB), considerou-se que essa modalidade de ensino deveria ter caráter emancipatório, contrapondo-se a ideia vigente por várias décadas. Com o estabelecimento da Lei no 9.394, em 1996, nasceu a Educação de Jovens e Adultos (EJA), que apontava para uma mudança mais significativa, pois trocou o termo "ensino" pelo termo "educação". O primeiro conceito indica "transmissão de conhecimento", ao passo que o segundo denota uma abrangência maior, envolvendo a discussão e a criticidade.

Segundo a atual diretriz nacional para a educação brasileira, a EJA deverá oportunizar condições adequadas ao seu alunado, contemplando seus interesses e considerando sua realidade como trabalhadores. Em meio aos artigos 37 e 38 da LDB, dedicados a essa modalidade, podemos observar que esses têm caráter compensatório e marginal (BRASIL, 1996).

Em linhas gerais, os artigos legais destinados à EJA asseguram que o poder público será o responsável para garantir a gratuidade da educação para os jovens e adultos. A idade mínima para poder ingressar no Ensino Fundamental foi reduzida para quinze anos; e dezoito anos para o Ensino Médio. Além disso, destaca-se que a "A verdadeira ruptura introduzida pela nova LDB com relação à legislação anterior reside na abolição da distinção entre os subsistemas de ensino regular e supletivo, integrando organicamente a educação de jovens e adultos ao ensino básico comum" (HADDAD; DI PIERRO, 2000, p.122).

A LDB mantém a noção de suplência a EJA, ou seja, a educação compensatória, onde a pouca notoriedade e investimento 
dado a esta modalidade de ensino a relegou, mais uma vez, à marginalização da população, o que conduz fatalmente à manutenção da hegemonia inerente ao capital, que resultará na não emancipação da classe trabalhadora.

A EJA, ao longo de sua trajetória, é colocada à margem da sociedade e dos incentivos do Estado e, consequentemente, esse caráter marginal é ainda mais intensificado na educação de jovens e adultos que estão cumprindo pena privativa de liberdade. Hora e Gomes (2007, p. 41) relatam que a EJA:

É colocada à margem pela sociedade e, perante o Estado, sua visibilidade ainda é menor, não tendo um atendimento eficiente do sistema público, principalmente no que se refere a questões que tangem tanto ao acesso quanto à permanência nas escolas. Segundo, porque quando tratamos de EJA na educação prisional, estamos trabalhando com jovens e adultos encarcerados, o que os torna ainda mais marginalizados, mais longe do alcance de seus direitos. Se o acesso a uma educação eficiente já é de certa forma negado a jovens e adultos que estão fora da vida criminosa, como ficam então aqueles que pagam pelos seus delitos na cadeia? (HORA; GOMES, 2007)

A memória da EJA nos leva à realidade atual de jovens e adultos excluídos, visto que:

[...] a educação popular, a EJA e os princípios e concepções que a inspiram na década de sessenta continuam tão atuais em tempos de exclusão, miséria, desemprego, luta pela terra, pelo teto, pelo trabalho, pela vida. Tão atuais que não perderam sua radicalidade, porque a realidade vivida pelos jovens e adultos populares continua radicalmente excludente. (ARROYO, 2005, p. 225)

Portanto, o ensino de jovens e adultos é influenciado por fatores sociais, culturais, econômicos e políticos, ou seja, mostra que as pessoas sofrem influência também do processo histórico, e que suas escolhas não são livres e autônomas, pois, segundo Marx 
(2006, p.15), "Os homens fazem a sua própria história, mas não a fazem segundo a sua livre vontade; não a fazem sob circunstâncias de sua escolha e sim sob aquelas com que se defrontam diretamente, legadas e transmitidas pelo passado".

\section{POLÍTICAS PÚBLICAS E EDUCAÇÃO DE JOVENS E ADULTOS ENCARCERADOS}

Os dados do Departamento Penitenciário Nacional revelam que o grau de escolaridade dos jovens e adultos encarcerados é baixo, percebe-se que os obstáculos e dificuldades enfrentadas pelas pessoas que estão ou estiveram cumprindo pena privativa de liberdade são frutos de uma conjuntura de repressão sociocultural, que vem se perpetuando ao longo da história. Pois o analfabetismo e o baixo grau de escolarização das pessoas em situação de privação de liberdade estão diretamente relacionados à negação do direito a educação que já advém dos inúmeros processos de exclusão social, ao qual o indivíduo foi submetido mesmo antes de ser levado à prisão (ARROYO, 2005).

A Educação de Jovens e Adultos em situação de privação de liberdade não é uma área de conhecimento dentro das Ciências da Educação, porém integra a modalidade complementar da Educação Básica. A Educação de Jovens e Adultos para pessoas "livres" ou "extramuros" é marcada por negativas de direitos e exclusão. No ambiente carcerário, esses aspectos são mais intensificados, historicamente inexistem ações institucionalizadas, o processo educativo na prisão encontra desafios ainda maiores no aspecto da oferta, continuidade e compreensão política do seu impacto social.

Os jovens e adultos que estão encarcerados, em sua grande maioria, têm uma trajetória assinalada pela exclusão de direitos tais como: saúde, transporte, lazer, segurança, moradia, educação e outros. Perante essa realidade de negação ou de não oportunidade de acesso aos direitos sociais, Arroyo $(2005$, p. 30) pontua que:

Os jovens-adultos não são acidentados ocasionais que, gratuitamente, abandonaram a escola. Esses jovens e adultos repetem histórias longas de 
negação de direitos. Histórias que são coletivas. As mesmas vivenciadas por seus pais e avós; por sua raça, gênero, etnia e classe social.

Di Pierro (2008, p. 375) corrobora, informando que: "Em tempos em que a miséria incrementou a criminalidade e fez crescer a população carcerária, ganham visibilidade também, os jovens prisioneiros cujo direito à educação continua vigente no cárcere".

Dessa forma, os jovens e adultos em situação de privação de liberdade sofrem os impactos da dupla exclusão, primeiro por serem das camadas populares da sociedade e não terem seus direitos garantidos, e segundo por estar presa, situação que irá repercutir em sua vida e fará com que a pessoa que passou pelo cárcere seja mais estigmatizada (ONOFRE, 2007). Para alargar as perspectivas de um futuro melhor e amenizar os impactos da prisão, a educação ofertada no ambiente penitenciário é um caminho. Mas, para isso, é necessário que essa educação reconheça as pessoas presas como sujeitos sociais, que estão inseridos em um contexto específico.

Não é possível entender-me apenas como classe, ou como raça ou como sexo, mas, por outro lado, minha posição de classe, a cor de minha pele e o sexo com que cheguei ao mundo não podem ser esquecidos na análise do que faço, do que penso, do que digo. Como não pode ser esquecida a experiência social de que participo, minha formação, minhas crenças, minha cultura, minha opinião política, minha experiência (FREIRE, 2007, p. 18).

A educação em espaço de privação de liberdade deve possibilitar uma formação que vá muito além do somente saber ler e escrever. Essa deve ter como fundamentação, a formação de um cidadão autônomo, crítico, que respeite as diferenças e a diversidade de cada sujeito. Trata-se de uma educação intercultural (FREIRE, 2007).

Os jovens e adultos encarcerados são portadores de conhecimento, que não podem ser excluídos no ato de sua formação, esses devem servir de base para instigar sua criticidade, pois geralmente os sujeitos que cumprem pena restritiva de 
liberdade nunca estudaram, ou tiveram os estudos interrompidos, no entanto, têm uma ampla experiência de vida que deve ser trabalhada na escola. Cada pessoa atribui um significado e um desejo que pretende alcançar através da educação, logo, a escolarização no cárcere deve enxergar os alunos como portadores de conhecimentos e histórias de vida, que devem ser respeitadas, reconhecidas e trabalhadas para que o aluno seja capaz de ressignificar sua vida (FREIRE, 2007).

É nesse sentido, que a aquisição do conhecimento não pode ser um processo mecânico, mas sim criativo, de entendimento do mundo econômico, social, cultural e político, porque "Fazer a História é estar presente nela e não simplesmente nela estar representado" (FREIRE, 1989, p.24).

É importante que a educação escolar dos jovens e adultos encarcerados seja ofertada levando em consideração as práticas sociais e culturais da pessoa presa, tendo em vista que "A leitura não é um ato solidário isolado dos problemas sociais. A leitura é interação verbal entre indivíduos socialmente determinados" (SOARES, 2003, p. 56).

Dessa forma deve-se respeitar o contexto histórico e social do alunado que vive em situação de privação de liberdade, pois os seus saberes "nascem" do meio social em que o educando está inserido, e o ensino torna-se mais significativo quando está relacionado à aquisição de competências e habilidades úteis à realidade concreta dos seus educandos (FREIRE, 2007).

Baratta (1990, p. 3 apud ARBAGE, 2017, p. 53), ao refletir a situação dos jovens e adultos em privação de liberdade, informa que:

Os muros da prisão representam uma barreira violenta que separa a sociedade de uma parte de seus próprios problemas e conflitos. Reintegração social (do condenado) significa, antes da modificação do seu mundo de isolamento, a transformação da sociedade que necessita reassumir sua parte de responsabilidade dos problemas e conflitos que se encontra "segregada" na prisão. Se verificarmos a população carcerária, 
sua composição demográfica, veremos que a marginalização é, para a maior parte dos presos, oriunda de um processo secundário de marginalização que intervém em um processo primário. É fato comprovado que a maior parte dos presos procedem de grupos sociais já marginalizados, excluídos da sociedade ativa [...].

A readaptação social da pessoa privada de liberdade só é efetiva quando a pessoa que está presa deixa o sistema prisional e passa a sobreviver sem cometer delitos. A educação pode colaborar com esse processo, uma vez que possibilita a ampliação de perspectiva de melhoria econômica, pois para ter acesso ao mercado de trabalho, o ensino escolar, na grande maioria dos casos, é um dos requisitos.

A educação é um direito público, subjetivo, inalienável, irrenunciável, que visa salvaguardar a dignidade humana. A educação enquanto política pública é um direito da pessoa em situação de privação de liberdade, uma vez que a pena de reclusão deve retirar somente a liberdade, devendo ser mantido todos os direitos não atingidos pela sentença ou pela lei (BRASIL, 1984).

A lei tem o condão de originar as políticas públicas, visto que:

A origem normativa da política pública, mesmo que resulte da iniciativa legislativa do governo, Poder Executivo, é o Poder Legislativo. No sistema constitucional brasileiro, as políticas públicas mais comumente se expressam por meio de leis. Vejase, a propósito, o artigo 165 da Constituição de 1988, que define os orçamentos públicos como instrumentos de fixação das "diretrizes, objetivos e metas" $\left(\$ 1^{\circ}\right)$, além das "prioridades" $\left(\$ 2^{\circ}\right)$ da administração pública. $\mathrm{O}$ mesmo artigo fala também em "planos e programas", confirmando a multiplicidade de formas que podem assumir as políticas públicas. (BUCCI 1997, p. 95 apud ARBAGE, 2017, p. 81) 
A oferta do ensino no ambiente carcerário acontece através da manifestação do Estado. Vejamos alguns conceitos de políticas públicas, a princípio.

Não existe uma única, nem melhor, definição sobre o que seja política pública. Mead (1995) a define como um campo dentro do estudo da política que analisa o governo à luz de grandes questões públicas e Lynn (1980), como um conjunto de ações do governo que irão produzir efeitos específicos. Peters (1986) segue o mesmo veio: política pública é a soma das atividades dos governos, que agem diretamente ou através de delegação, e que influenciam a vida dos cidadãos. Dye (1984) sintetiza a definição de política pública como "o que o governo escolhe fazer ou não fazer". A definição mais conhecida continua sendo a de Laswell, ou seja, decisões e análises sobre política pública implicam responder às seguintes questões: quem ganha o quê, por quê e que diferença faz. (SOUZA, 2006, p. 5 apud ARBAGE, 2017, p. 82)

As características essenciais das políticas públicas são:

A política pública permite distinguir entre o que 0 governo pretende fazer e o que, de fato, faz.

A política pública envolve vários atores e níveis de decisão, embora seja materializada através dos governos, e não necessariamente se restringe a participantes formais, já que os informais são também importantes.

A política pública é abrangente e não se limita a leis e regras.

A política pública é uma ação intencional, com objetivos a serem alcançados.

A política pública, embora tenha impactos no curto prazo, é uma política de longo prazo.

A política pública envolve processos subsequentes após sua decisão e proposição, ou seja, implica também implementação, execução e avaliação. (SOUZA 2006, p. 17-18 apud ARBAGE, 2017, p. 82) 
As políticas públicas são concebidas com determinados interesses, e esses nem sempre objetivam a emancipação, o cuidado e respeito com os marginalizados socialmente. As políticas públicas são inúmeras, por exemplo, políticas de segurança pública, de transporte, de assistência social, de saúde, de educação, entre outras. Este artigo trata da política educacional para as pessoas privadas de liberdade.

Ao advogar pelas políticas públicas educacionais para o ambiente carcerário, objetiva-se a implementação de ações que colaborem com a formação da pessoa em situação de privação de liberdade, para obtenção de uma educação de qualidade, melhor preparação para o mercado de trabalho, melhoria das condições de sobrevivências e consequentemente a diminuição da reincidência criminal. Nesse sentido, a educação ofertada na prisão, deve possibilitar ao sujeito a reformulação de conceitos, pois a escolarização é um fator primordial no desenvolvimento humano. $\mathrm{O}$ ensino precisa levar os encarcerados à reflexão, conscientização e à liberdade. Consoante aos ensinamentos de Freire (1989, p. 89) precisa-se de

\begin{abstract}
Uma educação que possibilitasse ao homem a discussão corajosa de sua problemática. De sua inserção nesta problemática. Que o advertisse dos perigos de seu tempo, para que, consciente deles, ganhasse a força e a coragem de lutar, ao invés de ser levado e arrastado à perdição de seu próprio "eu", submetido às prescrições alheias. Educação que o colocasse em diálogo constante com o outro. Que o predispusesse a constantes revisões $[\ldots]$, que o identificasse com métodos e processos científicos.
\end{abstract}

A educação no cárcere precisa ser crítica e questionadora, para isso deve levar em consideração o contexto social e os saberes dos discentes, para não pecar no cientificismo e menosprezar os saberes dos encarcerados. A instrução é uma ferramenta capaz de incentivar a construção de conhecimentos, de discussão de projetos de vida, é um elemento essencial na luta contra a exclusão social (FREIRE, 2007). 
Portanto, a educação é um direito social que o Estado tem o dever de assegurar às pessoas em situação de privação de liberdade, sendo essencial que as políticas públicas destinadas ao ambiente carcerário sejam específicas e que de fato contemplem as especificidades dos sujeitos, para que a escola na prisão não seja mais um ambiente multiplicador e intensificador das desigualdades sociais.

\section{POLÍTICAS EDUCACIONAIS PARA 0 SISTEMA PENITENCIÁRIO DO AMAPÁ}

As políticas públicas educacionais que regulamentam a oferta e operacionalização da educação no ambiente penitenciário amapaense são fundamentadas nas normativas legais, Internacionais e Nacionais. De acordo com a legislação pátria, o ambiente penitenciário é organizado em nível estadual, onde cada Estado dispõe de certo grau de autonomia e responsabilidade para criação e implementação de políticas púbicas. Neste sentido, abordaremos as normativas que regulamentam a educação para as pessoas em situação de privação de liberdade no Amapá.

A Constituição do Estado do Amapá, promulgada em dezembro de 1991, estabelece como um dos princípios fundamentais do Estado, o respeito à dignidade da pessoa humana, no artigo 5, inciso I ressalta que: "Todos são iguais perante a lei, sem distinção de qualquer natureza, [...]", e estabelece que todos têm direito ao acesso à educação, pois: "I - ninguém será privado do exercício de direito à saúde e à educação, [...]". Logo, todas as pessoas, incluindo, portanto, as que cumprem pena de privação de liberdade, têm garantido o direito social à educação (AMAPÁ, 1991).

No capítulo $3^{\circ}$ da Constituição Estadual, que trata especificamente da educação nos artigos 279 a 291, o art. 279 reforça que a educação é um direito de todos, e tem como objetivo:

[...] o pleno desenvolvimento da pessoa e a formação do cidadão; aprimoramento da democracia e dos direitos humanos; o respeito aos valores e ao primado do trabalho; a afirmação do 
pluralismo cultural; a convivência solidaria e serviço de uma sociedade justa, fraterna, livre e soberana (AMAPÁ, 1991).

Para que esses objetivos sejam alcançados, o poder público, segundo o parágrafo único do artigo 279, incentivará

[...] o desenvolvimento de propostas educativas diferenciadas, com base em experiências pedagógicas, através de programas especiais, como também a capacitação e habilitação de recursos humanos para a educação (AMAPÁ, 1991).

A Constituição, ao falar em propostas educativas diversificadas, abre a possibilidade para que cada escola tenha seu Projeto Político Pedagógico diferenciado e que atenda da melhor maneira possível ao seu público. Essa garantia é muito relevante, ao pensar na educação prisional, pois esse grupo tem características e peculiaridades que precisam de estratégias didáticas pedagógicas que favoreçam o aprendizado.

A Constituição Estadual, no art. 291, com intuito de atender às especificidades dos locais e ambientes onde a escola esteja, relata que:

O sistema de ensino do Estado poderá adotar calendário escolar adequado, diferenciado de acordo com as necessidades, peculiaridades e possibilidades de cada localidade ou comunidade onde a escola esteja sediada (AMAPÁ, 1991).

Vale enfatizar, que mesmo com a previsão constitucional, ainda não existe um calendário escolar adequado à realidade da Escola Estadual São José. No Estado do Amapá, essa é a escola responsável pela oferta da educação às pessoas em situação de privação de liberdade.

O artigo 284, da Constituição Estadual amapaense, indica a criação do plano estadual de educação. O qual foi instituído pela Lei $n^{\circ}$ 1.907, de 24 de junho de 2015, para vigorar no decênio de 20152025. O Plano estadual de educação, visa por meio da meta 9: "[...] disponibilizar, no mínimo, 25\% (vinte e cinco por cento) das 
matriculas para a EJA, nos ensinos Fundamental e Médio, na forma integrada à Educação Profissional" (AMAPÁ, 2015).

O plano para atingir a meta 9 estabelece a estratégia de que as pessoas em situação de privação de liberdade serão um dos públicos-alvo a serem alcançados pela educação de forma integrada à Educação Profissional; vejamos a estratégia 9.3:

Fomentar a integração da EJA com a Educação
Profissional, em cursos delineados nas
modalidades presencial e a Distância, tanto para a
zona urbana quanto para a rural, observando as
características do público demandante,
especialmente as das populações do campo,
itinerantes e das comunidades indígenas, negras,
quilombolas, extrativistas, ribeirinhas, privadas de
liberdade, e de assentamentos; (AMAPÁ, 2015).

Essa estratégia além de incentivar a integração da EJA à Educação profissional sinaliza que pretende estimular o uso das tecnologias ofertando a educação a distância (EAD). No que se refere à $E A D$ no ambiente penitenciário amapaense, existe uma longa distância entre o proposto e a realidade da penitenciária, pois somente a penitenciária masculina dispõe de um laboratório de informática, porém os alunos não utilizam porque no laboratório não tem acesso à internet. Frisa-se que no anexo da escola da penitenciária feminina não existe laboratório de informática.

O plano estadual de educação, na meta 10, pretende elevar os índices de alfabetização do público-alvo da EJA "[...] para 93,5\% (noventa e três inteiros e cinco décimos por cento), erradicar o analfabetismo absoluto e reduzir em $50 \%$ (cinquenta por cento) a taxa de analfabetismo funcional, até o final da vigência do Plano Estadual de Educação-PEE". Nessa meta, as pessoas em situação de privação de liberdade são incluídas expressamente na estratégia 10.7, ao pretender:

Assegurar, em regime de colaboração com os Munícipios, a oferta de EJA nas etapas de Ensino Fundamental e Médio, a pessoas privadas de liberdade, em todos os estabelecimentos socioeducativos e penais do Estado, observando a 
Resolução no 2/2010, do Conselho Nacional de Educação/Câmara de Educação Básica (CNE/CEB), que dispõe sobre as Diretrizes Nacionais para a oferta de educação para jovens e adultos em situação de privação de liberdade nos estabelecimentos penais; (AMAPÁ, 2015).

A estratégia 10.7 objetiva garantir a EJA nas etapas fundamental e médio em todos os estabelecimentos penais do Estado do Amapá, porém o Instituto de Administração Penitenciária do Amapá (IAPEN), que é composto por oito estabelecimentos prisionais, oferta a educação escolar somente na penitenciária masculina e feminina. Esses são os excertos do plano estadual de educação que falam expressamente da pessoa em situação de privação de liberdade, porém no decorrer do texto podemos encontrar direcionamentos à EJA que se aplicam à educação no ambiente penitenciário.

O Estatuto Penitenciário do Estado do Amapá foi promulgado pela Lei $n^{\circ}$ 0692, de 11 de junho de 2002, e estabelece que o cumprimento da sanção penal objetiva a reeducação, a reintegração social e evitar a reincidência, para assim proteger a sociedade. $\mathrm{O}$ artigo $3^{\circ}$ informa que: "No regime e no tratamento penitenciário serão observados o respeito e a proteção aos direitos do homem" (AMAPÁ, 2002).

O Estatuto Penitenciário prevê no artigo 35 que: "O tratamento penitenciário realiza-se através do desenvolvimento de atividades relacionadas com instrução, trabalho, religião, disciplina, cultura, recreação e esporte, contato com o mundo exterior e relações com a família". Percebe-se no campo normativo o interesse de trabalhar o ser humano em conjunto, levando em consideração vários aspectos que influenciam a vivencia social. Nesse enfoque, o artigo 42 estabelece que: "Para o bem-estar físico e mental dos sentenciados, serão organizadas, nos estabelecimentos penitenciários, atividades culturais, recreativas e esportivas". (AMAPÁ, 2002).

O Estatuto preconiza, no artigo 36, inciso IV que a assistência educacional compreende: 
a) a instrução escolar e a formação profissional do assistido, sob orientação pedagógica;

b) executar os métodos de tratamento de natureza pedagógica;

c) acompanhar diretamente o comportamento do assistido, com utilização das técnicas pedagógicas;

d) esclarecer ao assistido as peculiaridades e atividades ao seu alcance;

e) elaborar pareceres pedagógicos reeducativos para complementar

colaborar com o estudo da personalidade;

f) elaborar pareceres enfatizando as mudanças comportamentais do assistido, para fins de exames criminológicos.

Parágrafo único - Ao sentenciado será fornecido diploma ou certificado de conclusão de curso, que não mencionará sua condição de condenado. (AMAPÁ, 2002)

A assistência educacional de acordo com o Estatuto também poderá ser realizada por correspondência, rádio ou televisão, desde que não prejudique a disciplina e segurança do ambiente penitenciário. Será obrigatório o ensino de primeiro grau que deve ser integrado ao sistema escolar.

A educação profissional nos dizeres do artigo 39, "[...] será ministrado em nível de iniciação ou de aperfeiçoamento técnico. A mulher condenada terá ensino profissional adequado à sua condição".

O Estatuto Penitenciário prevê no artigo 40 que: "As atividades educacionais podem ser objeto de convênio com entidades públicas ou particulares que instalem escolas ou ofereçam cursos especializados". No artigo 41 é mencionado que cada estabelecimento penitenciário terá uma biblioteca com uma diversidade de livros instrutivos, didáticos e recreativos, para atender a todos os encarcerados. Porém, até o momento, é um direito que não foi concretizado, pois dos 08 (oito) estabelecimentos prisionais somente 02 (dois) têm biblioteca (AMAPÁ, 2002).

O Plano Diretor do Sistema Penitenciário do Estado do Amapá foi assinado pelo Secretário da SEJUSP e pelo Diretor do 
IAPEN, em 13 de março de 2008, por reconhecerem a relevância da parceria do Estado do Amapá com o Governo Federal, porém após 11 anos de elaboração, ele nunca passou por avaliação, e até o momento o IAPEN não dispõe de planejamento para realizar a atualização, por esse motivo as metas para a escola e a educação não será descrito, esse fato demostra no mínimo a falta de organização e planejamento com a realização do serviço prestado à sociedade, dando a entender que foi elaborado com o intuito de atender à exigência do Departamento Penitenciário Nacional (AMAPÁ, 2008).

No Estado do Amapá, a Secretaria de Estado da Educação (SEED) emitiu, pelo Conselho Estadual de Educação (CEE), a Resolução Normativa No 57/2015 - CEE/AP, a qual regulamenta a oferta da educação de jovens e adultos e a educação profissional e tecnológica, para todas as pessoas em situação de privação de liberdade, incluindo, portanto, os presos provisórios, sentenciados, egressos do sistema prisional e aqueles que cumprem medidas de segurança. A resolução também apregoa que a educação básica poderá ser ofertada mediante a celebração de convênios e/ou parcerias com instituições governamentais ou não governamentais (AMAPÁ, 2015).

A resolução atribui à SEED, em articulação com a administração penitenciária, a responsabilidade pela oferta da educação, a qual deve respeitar os valores e realidade expostos no Projeto Político Pedagógico (PPP). No entanto, ocorre que o PPP da Escola Estadual São José ainda não foi aprovado, sua última versão incompleta é do ano de 2014, ou seja, além de inacabado é desatualizado. O Projeto Político Pedagógico da Escola Estadual São José, deveria ser o instrumento norteador das atividades educativas por meio do qual seriam definidas as prioridades, objetivos e metas a serem alcançadas.

A Resolução Normativa No 57/2015 estabelece as referências mínimas do que deve conter no Projeto Político Pedagógico. E prevê no artigo $6, \S 2^{\circ}$, que poderão ser contempladas no PPP, desde que devidamente fundamentadas "As atividades laborais, artístico-culturais, de esporte e lazer e outras previstas nesta 
Resolução, deverão ser realizadas em condições e horários compatíveis com as atividades educacionais, [...]" (AMAPÁ, 2015).

A resolução no artigo $1^{\circ}, \S 4^{\circ}$ sinaliza que deve existir a troca de informações entre a penitenciária e a escola, pois: "A administração penitenciária deverá informar a escola de Referência que o aluno recebeu alvará de soltura que imediatamente deverá providenciar a documentação escolar". No decorrer da coleta dos dados documentais constatou-se que esse parágrafo não vem sendo cumprido, pois na escola os servidores não sabem informar os motivos pela desistência, ficando na dúvida se o aluno saiu de alvará, se não vai estudar porque não quer, se saiu de licença temporária e outros, ou seja, ainda não existe um mecanismo de controle e comunicação efetivo entre escola e penitenciária (AMAPÁ, 2015).

A resolução informa que o ensino de jovens e adultos em situação de privação de liberdade, será financiado com recursos públicos de manutenção e desenvolvimento do ensino, como o Fundo de Manutenção e Desenvolvimento da Educação Básica e Valorização do Magistério (FUNDEB) e outros recursos advindos das fontes estaduais e federais (AMAPÁ, 2015).

A educação no ambiente carcerário atentará para a rotatividade, de tempo, local e espaço. Segundo o artigo 2, inciso V:

Será contemplado o atendimento em todos os turnos, respeitando o que preceitua a legislação vigente, principalmente a normatização estadual da educação de jovens e adultos no que diz respeito à carga horária, currículo, planejamento, organização escolar e formas de avaliação, conforme as necessidades e condições operacionais dos estabelecimentos prisionais; (AMAPÁ, 2015).

A escolarização dos jovens e adultos no ambiente obedecerá às seguintes orientações, estatuídas no art. $2^{\circ}$ :

II - levar-se-á em conta ações complementares de cultura, esporte e lazer, inclusão digital, educação profissional e tecnológica, geração de emprego e 
renda, fomento à leitura e a programas de implantação, recuperação e manutenção de bibliotecas destinadas à população privada de liberdade, inclusive as ações de valorização dos profissionais que trabalham nesses espaços;

III - promoverá o envolvimento da comunidade e dos familiares dos indivíduos em situação de privação de liberdade e preverá atendimento diferenciado de acordo com as especificidades de cada medida e/ou regime prisional, considerando as necessidades de inclusão e acessibilidade, bem como as peculiaridades de gênero, raça e etnia, credo, idade e condição social da população atendida;

IV - deverão ser desenvolvidas políticas de elevação da escolaridade associada à qualificação profissional e tecnológica, articulando-as, também, de maneira intersetorial, a políticas e programas destinados aos jovens e adultos; (AMAPÁ, 2015).

É mencionado na resolução que os responsáveis pela educação no ambiente prisional deverão oferecer espaços físicos contando com completa instalação de materiais e equipamentos adequados às atividades educacionais, esportivas, de formação profissional, de lazer, culturais, de acessibilidade e outros, integrando-as às rotinas dos estabelecimentos penais.

A resolução também contempla a formação inicial e continuada aos educadores, gestores, técnicos e pessoal de apoio, que laboram nos ambientes penitenciários. Essa formação deverá considerar as peculiaridades da execução penal e a relevância da educação formal no processo de readaptação da pessoa privada de liberdade (AMAPÁ, 2015).

A resolução no artigo 10 estabelece que: "O Plano Estadual de Educação do Amapá deverá incluir objetivos e metas de educação em espaços de privação de liberdade que atendam às especificidades dos regimes penais previstas no Plano Nacional de Educação". Porém, o atual Plano Estadual (2015-2025) não elaborou metas e objetivos específicos para a educação prisional.

No parágrafo único do artigo 10, é fixado que: "O Plano Estadual de Educação nas Prisões do Amapá será um dos 
documentos de referência em todas as ações relacionadas à educação no sistema prisional do Estado". Ocorre que esse documento que deveria servir de base para a educação prisional até o momento não foi aprovado (AMAPÁ, 2015).

A resolução no art. 11 define que:

Compete ao Conselho Estadual de Educação do Amapá atuar na fiscalização e acompanhamento da implementação destas normas, articulando-se em regime de colaboração, com a Secretaria de Estado da Educação, com os Conselhos Municipais de Educação e demais instituições e órgãos de execução penal que desenvolvam ações voltadas para defesa e garantia de direitos das pessoas privadas de liberdade e dos egressos do Sistema Prisional (AMAPÁ, 2015).

Ainda no que se refere a normativas para a educação penitenciária no Amapá, destaca-se a Portaria 001/2019 da VEP, de 12 de março de 2019, que disciplina a remição pela leitura no sistema penitenciário do Amapá para os presos dos regimes fechado, semiaberto, aberto e pessoas presas provisoriamente, cujos dias passíveis de remição serão computados se sobrevier à sentença. Porém, ainda não foi efetivada e os presos permanecem sem o direito da remição pela leitura.

Portanto, essas são as normativas amapaenses que tratam da educação na prisão. Da breve análise, fica claro que os órgãos fiscalizadores da execução penal e da Administração Pública (Secretária de Educação e Secretária de Justiça), precisam sair do campo das leis para a fiscalização e aplicação do que está regulamentado e que é direito da pessoa em situação de privação de liberdade.

\section{CONSIDERAÇÕES FINAIS}

Do breve contexto da educação de jovens e adultos e da apresentação do público dessa modalidade educativa na sociedade extramuros, é nítida a similaridade com a pessoa que está presa, pois o público da EJA tanto na sociedade intramuros como 
extramuros é em sua maioria do mesmo estrato social, são cidadãos que enfrentam cotidianamente o desrespeito, a insuficiência ou a ausência dos direitos sociais, dentre eles, a educação.

Os dispositivos legais asseguram a educação das pessoas em situação de privação de liberdade como um direito humano fundamental, haja vista que a sentença deve limitar somente a liberdade. No entanto, o direito à educação no ambiente penitenciário ainda encontra obstáculo na efetivação.

Nesse sentido, é fundamental estimular o debate nos espaços políticos, acadêmicos, religiosos, associações e nos mais diferentes contextos, pois o ambiente penitenciário atinge direta ou indiretamente todas as pessoas, por isso fomentar as discussões é imprescindível para que os órgãos fiscalizadores se mobilizem em prol da realização da fiscalização da implementação da lei.

Portanto, a correta aplicação da legislação pode trazer avanços significativos para a sociedade, logo é fundamental que a fiscalização aconteça. A pesquisa aponta que ainda é necessária a aprovação de normativas específicas para o ambiente prisional amapaense como, por exemplo: o Plano Estadual de Educação para as Prisões, e a efetivação da remição pela leitura.

\section{REFERÊNCIAS}

AMAPÁ. Conselho Estadual de Educação do. Resolução Normativa $n^{\circ} 057$ de 2015. Dispõe sobre a oferta da educação de jovens e adultos e da educação profissional e tecnológica para pessoas privadas de liberdade, nos estabelecimentos penais do Estado do Amapá e dá outras providências correlatas. Amapá: Conselho Estadual de Educação, 2015.

AMAPÁ. Constituição do Estado do Amapá. 1991. Disponível em: https://editor.amapa.gov.br/arquivos_portais/publicacoes/SEAD_0ea 123298178456301d051e08f184dea.pdf. Acesso em: 20 ago. 2017.

AMAPÁ. Disciplina a remição pela leitura no âmbito do sistema prisional para os regimes fechado, semiaberto e aberto da Comarca de Macapá no Estado do Amapá. Portaria nº1/2019VEP. Macapá, 2019. 
AMAPÁ. Estatuto Penitenciário do Amapá. Lei Nº 0692, de 11 de junho de 2002. Dispõe sobre normas de execução penal no Estado do Amapá e dá outras providências. Diário Oficial do Estado: Macapá, 08 jul. 2002. Disponível em:

http://www.al.ap.gov.br/ver_texto_consolidado.php?iddocumento $=1$ 7320\#: :text=1\%C2\%BA\%20Esta\%20Lei\%20regula\%20a,\%C3\%A0\%2 0sua\%20reintegra\%C3\%A7\%C3\%A3o\%20na\%20sociedade.. Acesso em: 20 ago. 2017.

AMAPÁ. Lei No 1.907, de 24 de junho de 2015. Dispõe sobre o Plano Estadual de Educação - PEE, para o decênio 2015-2025, e dá outras providências. 2015. Disponível em:

http://www.mpap.mp.br/menu-legislcao?view=article\&id=6685:leiap-1907-2015\&catid=16. Acesso em: 20 ago. 2017.

AMAPÁ. Plano Diretor do Sistema Penitenciário do amapá. Macapá, 2008.

ARBAGE, L. A. Ressocialização por meio da educação: um estudo de caso em Florianópolis-SC. 2017. 169f. Dissertação (Mestrado em Educação) - Centro de Educação, Universidade Federal da Fronteira Sul, Chapecó, 2017. Disponível em:

https://rd.uffs.edu.br/bitstream/prefix/1140/1/ARBAGE.pdf. Acesso em: 18 dez. 2018.

ARROYO, M. G. "Educação de jovens-adultos: um campo de direitos e de responsabilidade pública" In: SOARES, L., GIOVANETTI, M. A., Gomes, N. L. (orgs.). Diálogos na educação de jovens e adultos. Belo Horizonte: Autêntica, 2005.

BRASIL. Constituição da República Federativa do Brasil. 1988. Brasília: Senado Federal, 2001.

BRASIL. Lei nº 7.210 de 11 de julho de 1984. Lei de Execução Penal. Institui a Lei de Execução Penal. Diário Oficial [da] República Federativa do Brasil, Brasília, 11 jul.1984. Disponível em: http://www.planalto.gov.br/ccivil_03/leis//7210.htm. Acesso em: 26 jul. 2017.

BRASIL. Lei No 9.394 de 20 de dezembro de 1996. Lei de Diretrizes e Bases da Educação Nacional. Estabelece as Diretrizes e Bases da 
Educação Nacional. Diário Oficial [da] República Federativa do Brasil, Brasília, 23 dez.1996. Disponível em: :http://www.planalto.gov.br/ccivil_03/leis/19394.htm. Acesso em: 28 jul. 2017.

COSTA, C. D. M.; OLIVEIRA, P. C. S. Alfabetização, letramento e Educação de Jovens e Adultos. In: SOARES, L. (org.). Educação de Jovens e Adultos: o que revelam as pesquisas. Belo Horizonte: Autêntica, 2011.

DEPARTAMENTO PENITENCIÁRIO NACIONAL. Sistema Integrado de Informações Penitenciárias. Brasília: Ministério da Justiça, 2019. Disponível em:

http://antigo.depen.gov.br/DEPEN/depen/sisdepen/infopen/relatori os-sinteticos/infopen-jun-2017-rev-12072019-0721.pdf. Acesso em: 26 jul. 2017.

DI PIERRO, M. C. Trajetória recente da educação de jovens e adultos na América Latina e Caribe. Cadernos de Pesquisa, São Paulo, v. 38, n.134, p.34-47, maio/ago. 2008.

FREIRE, Paulo. A importância do ato de ler, em três artigos que se completam. São Paulo: Cortez, 1989.

FREIRE, P. Pedagogia da Autonomia: saberes necessários à prática educativa. São Paulo: Paz e Terra, 1996.

FREIRE, P. Política e Educação. 8.ed. Idaiatuba-SP: Villa das Letras, 2007.

GADOTTI, M. Educação de Jovens e Adultos: teoria, prática e proposta. São Paulo: Cortez, 2003.

HADDAD, S.; DI PIERRO, M. C. Escolarização de jovens e adultos. Revista Brasileira de Educação, n. 14, maio/ago. 2000.

HORA, D. M.; GOMES, P. R. Educação prisional: o problema do ponto de vista do currículo. BRASIL, MEC-SEED. EJA e Educação Prisional. Boletim maio 2007, p 34-42. (Salto para o Futuro).

MARX, K. Dezoito de Brumário. São Paulo: Martins Fontes, 2006. 
ONOFRE, E. M. C. Escola da Prisão: Espaço de construção da identidade do homem aprisionado? In: Educação escolar entre as grades. São Carlos: EdUFSCAR, 2007.

SOARES, M. B. As condições sociais da leitura: uma reflexão em contraponto. São Paulo: Martins Fontes, 2003.

Submetido em: Maio/ 2020.

Aceito em: Janeiro/ 2021. 